functions - also seems to explain why music therapy helps patients who have lost the ability to speak.

Many of Sacks's stories portray the striking independence of different cognitive abilities. We know of people who are tone-deaf; others may be 'rhythm-deaf', or have 'dysharmonia' - the inability to sense the harmonies created by multiple voices or instruments. After suffering brain damage in a car accident, a musician became unable to hear a string quartet as anything but separate voices: "Four thin, sharp laser beams, beaming to four different directions." Perhaps the most distressing syndrome is 'dystimbria', in which musical tones are perceived as unpleasant noises, akin to banging pots and pans or the screeching of a car. Incredibly, Sacks experienced two episodes of temporary dystimbria, during which piano music sounded like "toneless banging with an unpleasant metallic reverberation".

Of course, music speaks to our emotions as well as our intellect, and Sacks presents evidence that the emotional response has its own network in the brain. He also reminds us that music engages our motor circuits (think of foot-tapping and dancing) - a phenomenon that underlies the use of music therapy to 'unlock' patients who have been immobilized by Parkinson's disease.

Sacks's great gift - as a physician as well as a writer - is to see the whole person, rather than just the brain or the disease. He certainly avoids the danger he identifies in his preface: that, as new technologies allow us to examine the brain in ever-greater detail, "the simple art of observation may be lost ... clinical description may become perfunctory, and the richness of the human context ignored". Amidst the wealth of wonderful observations and the superabundance of humanity, another danger lurks: that the general reader who was hoping for a clear picture of what we know about the neuroscience of music may come away wanting more.

Help is at hand, in the shape of Levitin's very different but equally enlightening book. Levitin is ideally placed to write about music and the brain, having been a professional musician, sound engineer and record producer before embarking on a career as an academic neuroscientist. He starts with the basics: the physics and neuropsychology of pitch, timbre, rhythm, loudness and harmony. He then discusses the importance of processes such as perceptual completion ('filling in'), feature extraction and feature integration, and describes where they take place in the brain. The comprehensive bibliographic notes provide easy access to the relevant technical literature.

Levitin is just as interested as Sacks in the emotional power of music, but where Sacks tells us of unfortunate individuals who have lost the ability to be moved by music, Levitin offers a mechanistic explanation for its effects. "Music communicates to us emotionally," he says, "through systematic violations of expectations." He also presents evidence for the neural circuit that mediates the emotional response, which involves the cerebellum (the brain region that 'notices' deviations from the expected timing), the mesolimbic system (known to be involved in pleasure, reward and addiction), and the release of dopamine by the nucleus accumbens. A separate circuit involving the auditory cortex looks after our intellectual response, the perception of structure and form.

Can the emotional effect of music really be summed up as the violation of expectations? When I'm listening to something as gutwrenching as the final movement of Tchaikovsky's sixth symphony, it certainly doesn't feel that way. But Levitin makes a persuasive case that memory, anticipation and surprise are fundamental to our enjoyment of music.

Levitin writes clearly and entertainingly, and has a real flair for analogy. His dual background adds to the fun. In one chapter we find him at lunch with Francis Crick, discussing the cerebellum; in the next, he's at dinner with Joni Mitchell, figuring out why her harmonies sound like no one else's (and why the bass player Jaco Pastorius was essential to her sound).

Both Levitin and Sacks are struck by the ubiquity of music across cultures and times, and by the observation that our brains seem to be, in Sacks's words, "exquisitely tuned for music". They vigorously rebut Steven Pinker's view of music as "useless", with no adaptive value, by asserting its importance in courtship, social cohesion, cognitive development and recall, and in simply making life more bearable. What tipped the balance for me, though, was learning from Sacks that, having no accurate timepieces available, Galileo timed his experiments on the descent of objects by humming tunes to himself. What could be more useful?

Laura Garwin is a postgraduate trumpet student at the Royal College of Music in London. She is a former North American editor of Nature and former executive director of the Harvard Bauer Center for Genomics Research.

\title{
Using maths to tackle cancer
}

\section{Dynamics of Cancer: Incidence, Inheritance, and Evolution \\ by Steven A. Frank \\ Princeton University Press: 2007.400 pp. $\$ 99.50, £ 59.95$}

\section{Robert A. Weinberg}

Multicellular animals have been around for about 600 million years, and cancer has been a problem for most of this time. There is a risk of cancer whenever the component cells grow and divide, so cancer incidence has increased progressively as the size and lifespan of organisms extended. In a lifetime, humans experience up to $10^{16}$ mitoses, the process by which a cell duplicates its DNA and divides to make two identical daughter cells. Each mitosis is an invitation to genetic disaster, due to miscopying of DNA, inadvertent breakage of chromosomes, and mishaps in chromosomal segregation. Given these vast opportunities for accumulating mutations, it is surprising that we don't generate numerous life-threatening cancerous cell clones during our first years of life.

The reason for our long and generally cancer-free lives is a series of anticancer defence mechanisms that have co-evolved with our increasing complexity. Most of these defences are wired into the intracellular signalling circuits that govern cell behaviour, although the organization of our tissues and immune systems contributes too. At least five or six of these mechanisms must be breached before a

\section{Academic Charisma and the Origins of the Research University}

by William Clark (Univ. Chicago Press, \$22.50)

We'd like to think that the modern university

developed naturally from the high-minded pursuit of knowledge for its own sake. But William Clark argues that market forces and bureaucracy in eighteenthcentury Germany played a large part by creating an environment in which academics achieved success by publishing their results.

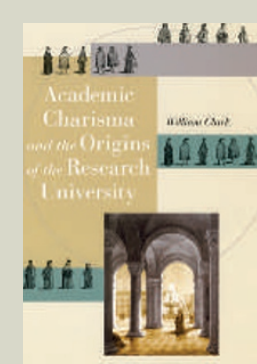

\section{Stephen Hawking: A Biography}

by Kristine Larsen (Prometheus, \$16.95)

Astronomer Kristine Larsen's wide-ranging account provides a fascinating insight into the life and work of one of the past century's most remarkable scientists. She reveals how Stephen Hawking - who recently co-wrote the children's book George's Secret Key to the Universe - came to terms with Lou Gehrig's disease and explains the ideas that took cosmology to the top of the bestseller lists.

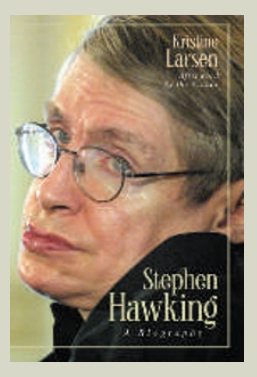




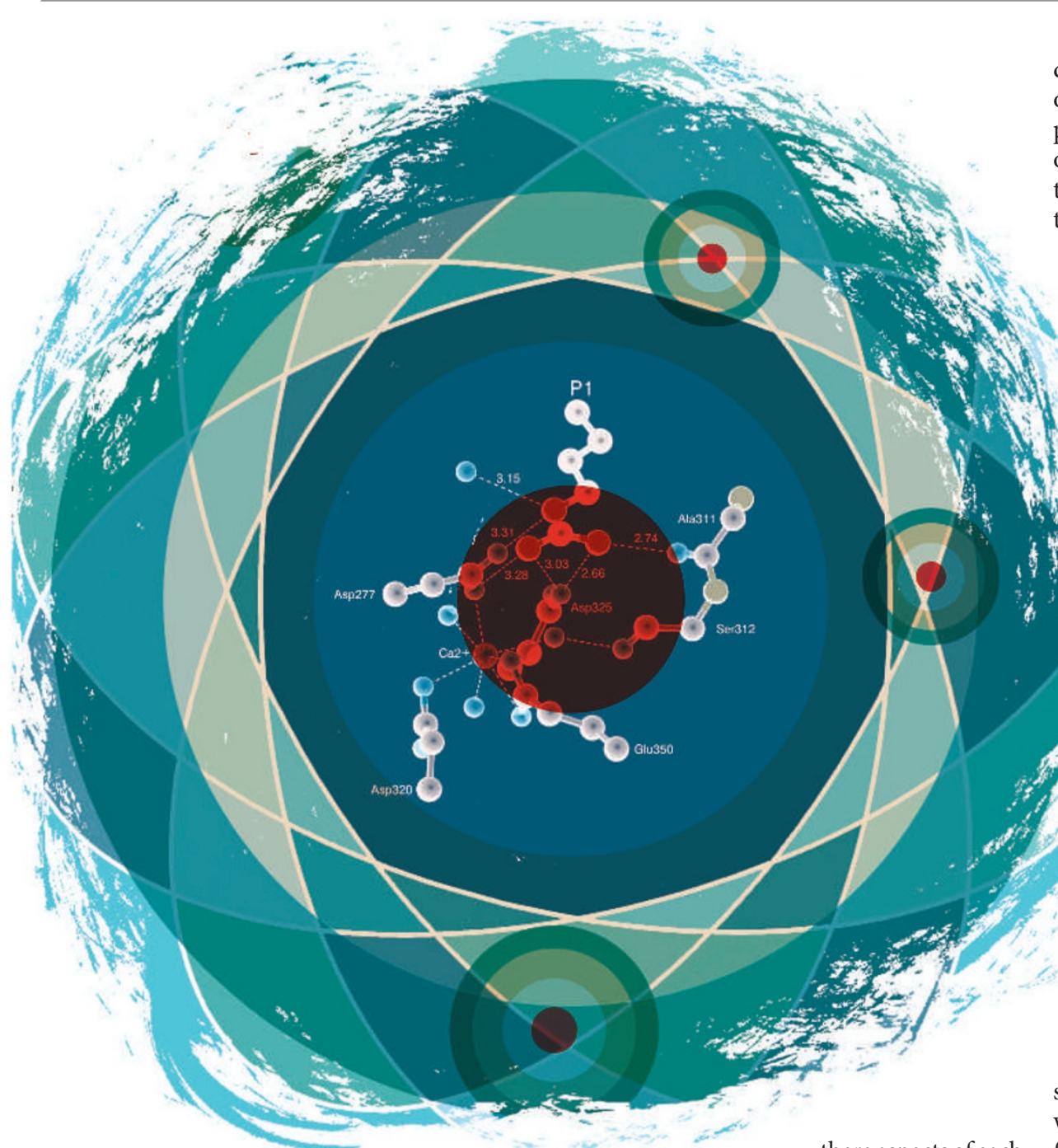

full-blown

tumour appears.

These multiple lines of defence explain the complexity of tumour formation, which in most tissues involves a sequence of steps, each of which breaches one or more of the defences. We can describe some of these steps in biochemical detail, such as the activation of a ras oncogene or the inactivation of the $p 53$ tumour-suppressor gene. But a description of the process as a whole is currently well beyond our reach.

Steven Frank, in his new book Dynamics of Cancer, is the latest in a line of biologists and mathematicians who have taken on the challenge. Can we describe tumour formation in terms of rate equations and probabilities? Are question of whether we know enough biology and biochemistry to create truly useful, predictive models of multi-step tumour development. We have learned much over the past three decades about the biochemistry of cell transformation and the physiology of neoplastic cell growth, but we still have only a crude understanding of how these processes play out in living tissues. We don't understand in any quantitative way how endogenous mutagenic processes and environmental mutagens work. Nor do we understand the mechanisms or the kinetics governing the methylation of gene promoters and the resulting silencing of tumoursuppressor genes.

The fate of most of the preneoplastic cell clones remains an enigma. We don't understand how specific mutant alleles or mutant oncoproteins affect the darwinian processes of clonal selection and expansion. In fact, we don't really know how many distinct biological steps drive or accompany the formation of any type of human tumour. We know the approximate number of the slowest, rate-limiting steps, but almost nothing about the more rapid ones, yet these are just as important in driving multi-step tumour progression.

Frank is an evolutionary biologist with a strong mathematics bent. His book grapples with many of these issues, offering insights from his mathematical modelling of various steps of tumour progression. Those who aspire to digest all of his arguments, many of which are embedded in equations, will not find this step that can be reduced to mathematical formulation? And can we develop a general model of multistep tumorigenesis as it occurs in a variety of human tissues?

Solutions to these problems have ramifications beyond our understanding of tumorigenesis. For example, if we could assign values to the parameters governing the rates of each step of tumorigenesis, including

"Can algebraic formulae tell us more than reasoning about the behaviour of complex biological systems?" the ways environmental and genetic factors affect these parameters, we could predict why cancer strikes at certain ages and in certain individuals.

Frank's approach to this problem raises the easy reading. The text often appears in the formal voice of a mathematical proof.

A school of mathematical biology arose at the University of Chicago in the 1960s, only to decline in the following decade. It became apparent that a multitude of parameters needed to be assumed or arbitrarily fitted to existing data sets to ensure that the predictive powers of mathematical models conformed with actual observations. In the end, the proponents of mathematical biology drifted

\section{The Trouble With Physics}

by Lee Smolin (Houghton Mifflin, \$15.95)

The publication of Smolin's book and Not Even Wrong (see right) last year split the physics community with their claim that string theorists are undermining the whole scientific enterprise by turning their backs on the need for testable predictions (see Nature 443, 491; 2006). George Ellis wrote that, "Smolin crystallizes what many in the physics community feel about these extravagances" (Nature 443, 507-508; 2006).

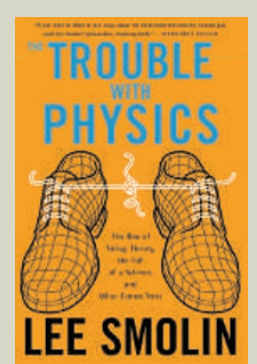

Not Even Wrong: The Failure of String Theory and the Search for Unity in Physical Law by Peter Woit (Basic Books, \$16.95)

Vociferous mathematician and blogger Peter Woit, like Smolin (see left), raises hackles by arguing that string theory is a blind alley. He also expounds his view of why, culturally and sociologically, theorists have continued to focus time and money on something for which, in his opinion, they have no corroboration despite 20 years of graft.

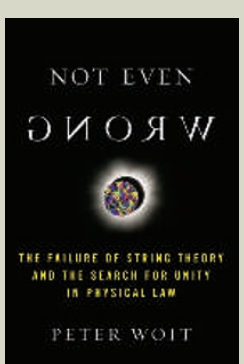


away, disenchanted.

Perhaps the biologists posed the most pointed question: can algebraic formulae tell us more than reasoning about the behaviour of complex biological systems? This question echoes almost half a century later, but Frank is undeterred. One day he may be seen as the pioneer who began the difficult task of building a sturdy foundation for a truly useful mathematical model of cancer development.

Robert A. Weinberg is at the Whitehead Institute for Biomedical Research, Massachusetts Institute of Technology, Cambridge, Massachusetts 02142, USA.

\section{One-man canary}

\section{Suffer and Survive: The Extreme Life of \\ J. S. Haldane \\ by Martin Goodman \\ Simon \& Schuster: 2007.320 pp. $£ 14.99$ \\ (Not available in the United States)}

\section{Andy Meharg}

That the nineteenth-century physician J. S. Haldane lived to his mid-70s was more down to luck than self-preservation. In his study of respiration and lung disease, Haldane performed series after series of experiments on himself, any one of which could have been fatal. In an air-tight chamber he systematically exposed himself to dangerous levels of toxic gases for extended periods to see how his body would react, his only precaution being a colleague watching through a window to see when he collapsed.

What drove Haldane was his innate scientific curiosity and a desire to save others' lives. $\mathrm{He}$ worked tirelessly to protect miners from the perils of coal dust, methane, carbon monoxide, carbon dioxide and low oxygen levels. He would rush to mine disasters to experience the fatal vapours and so determine the cause of death. He devised safety measures, such as his famed canary cage with a built-in oxygen supply to revive the bird when it collapsed. And by telling Cornish miners to spray the rock face with water as they cut, to reduce dust, he saved thousands from an early and painful death from the lung disease silicosis.

When German chemist Fritz Haber developed chemical warfare during the First World War, the British government turned to Haldane to protect the troops. There followed an arms race as Haber tried to outwit Haldane's development of gas masks. In the course of this work, Haldane frequently exposed himself to chlorine and mustard gases used on the battle- field. He conducted research on the front line to work out what gases were being used, and gauged their physiological impact by autopsying dead soldiers. He also pioneered the oxygen treatment used to recuperate soldiers who survived gas attacks.

Haldane's war effort went beyond the trenches. His work on deep-sea diving and the atmosphere in submarines saved many lives, and his studies of high altitudes benefited pilots and laid the way for the conquest of Mount Everest. It was Haldane who discovered that the body produces extra haemoglobin during acclimation to low oxygen at high altitudes.

The life of this fearless man is neatly laid out in Martin Goodman's biography Suffer and Survive. Goodman conveys Haldane's scientific dynamism and his love for life. Haldane was interested in philosophy, music and theatre, and had a fascinating family and social circle: the writer Aldous Huxley was a suitor for his daughter, for example, and novelist J. M. Barrie was a guest at his

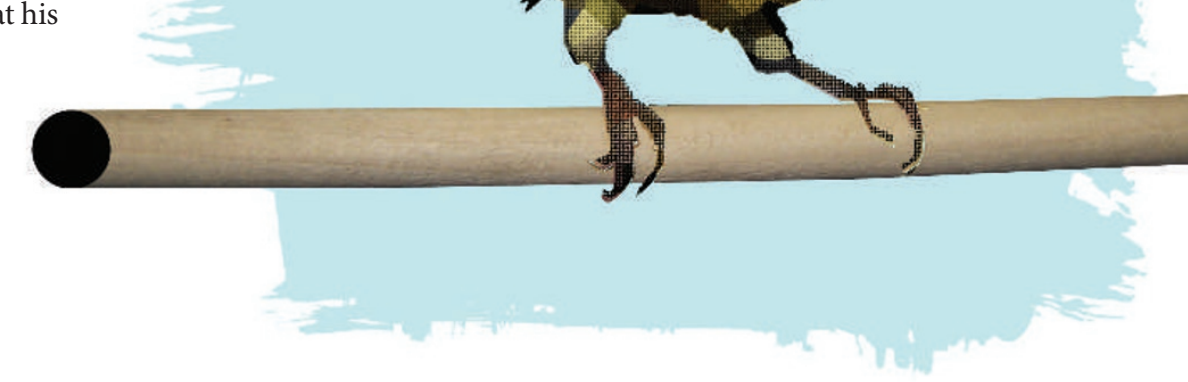

Scottish estate. In 1912, using a scientific mission as cover, Haldane accompanied his brother Richard - secretary of state for war and later the first Labour lord chancellor - to Germany for secret negotiations with the Kaiser to avert war.

This fine book is not without fault. The first chapter has vividly imagined scenes embroidered onto real events, presumably for dramatic effect, describing how Haldane rushed to a Welsh coal-mining accident. This device is thankfully used less in subsequent chapters. However, it is not until 100 pages in that descriptions of Haldane's experimental gas chamber and his measurements of carbon dioxide and carbon monoxide in blood, so central to the opening chapter, are outlined. After this shaky start, the book becomes highly enjoyable. It is a fitting tribute to a pioneer who enabled the human body to survive at the extremes of modern life.

Andy Meharg is professor of biogeochemistry at the University of Aberdeen, Cruickshank Building, St Machar Drive, Aberdeen AB24 3UU, UK, and is the author of Venomous Earth: How Arsenic Caused the World's Worst Mass Poisoning. 